\title{
Personal vitality and its manifestations in difficult life situations and environmental conditions
}

\author{
Elena Tkach $^{1, *}$ and Aida Simakhina ${ }^{1}$ \\ ${ }^{1}$ Pacific National University, Karl Marx Street, 68, 680013, Khabarovsk, Russia
}

\begin{abstract}
The article is devoted to the comprehension of the problem of manifestation of personal vitality and its manifestations in difficult life situations, presented in the works of various researchers-psychologists. Vitality is seen as the ability to cope with one's own life, the result of positive adaptation despite adverse conditions and / or dangerous circumstances. Vitality is characterized by a combination of social and intrapsychic processes that allow a person to be healthy in an unfavorable environment. The manifestation of a person's ability to cope with difficult circumstances, unfavorable life situations is influenced by various factors, including the possibility / impossibility of productive self-expression, sufficient involvement / non-involvement in taking care of oneself and important life processes, searching and finding a solution to the problem of lack of motivation, openness / closeness, awareness / lack of awareness, etc. An essential point in the development of a person's vitality is the provision of the necessary specially organized psychological assistance aimed at optimizing the client's self-esteem, developing his assertiveness, sense of humor, flexibility, creativity, motivational-semantic sphere and reflective culture.
\end{abstract}

\section{Introduction}

The study of human vitality occupies a special position in psychological science. From the first studies in the 1970s to the present, a large amount of empirical data, numerous theoretical developments and practical interventions have been accumulated. The importance and relevance of studies of viability is increasing in the context of significant socio-economic changes, the emergence of new global risks, changing living conditions and social institutions, the emergence of new types and conditions of education and training. The application of various knowledge gained in the study of vitality can contribute to the provision of productive psychological assistance aimed at the development of a viable personality, which acquires the ability to positively adapt despite various adverse conditions and dangerous circumstances. We are talking about the development of some invulnerability in difficult life situations, when a person is faced with stress of a destructive nature, but so

\footnotetext{
${ }^{*}$ Corresponding author: ellenp12@gmail.com
} 
effectively uses the ability to cope with behavior that this leads to minimization of energy costs.

It should be noted that in Russia the study of viability is a fairly young direction. Russian researchers began to actively develop this topic only since the 2000 s.

The topic of viability today, during the period of sanitary and epidemiological restrictions associated with the COVID-19 pandemic, is gaining special importance, since a large number of people are faced with stress caused by the inability to move freely, travel, and communicate a lot live. Many people find themselves in circumstances of lack of choice. These circumstances give rise to a lot of fear and anxiety. The number of people experiencing depressive states is significantly increasing. There is a lot of uncertainty and lack of guarantees in life. The level of entropy increases significantly. The person becomes vulnerable. In connection with these circumstances, the study of the viability of the personality and its manifestations is becoming increasingly relevant.

\section{Materials and methods}

The main research method was the method of analysis of psychological literature on the problem under study.

Viability studies are presented in the works of various authors [1-8].

In the broadest sense of the word, vitality means the ability of each person to overcome various obstacles that occur on his life path and depend on family, social, cultural and other circumstances of a person's daily life.

A person with a high level of vitality has high self-esteem. He is the subject of productive interpersonal relationships. Such a person has an active life position. He is confident in his abilities and other people.

The most accepted interpretation in the scientific psychological space reduces vitality to a person's ability to positively adapt, despite unfavorable circumstances.

An important achievement of the study of resilience was the understanding and comprehension of the idea that the identification of positive developmental practices in the context of difficult circumstances is essential for the prevention and correction of developmental disorders, and the effective formation of the personality.

\section{Results}

Analysis of various scientific sources has shown that different authors have proposed many different interpretations of the phenomenon under study and its definitions. Most researchers argue that vitality is manifested precisely in the interaction of person and the environment. In this context, the interaction of risk factors emanating from the environment and protective factors of the resource potential of the person himself is investigated. Vitality is viewed as a product of social interaction, human involvement in social networks, human interaction with the media. Vitality is assessed as the product of various combinations of variables influenced by biological, social, cultural, psychological factors and conditions.

The so-called individual approach to understanding the manifestations of vitality is focused on describing vitality as an "internal" phenomenon, the formation and development of which depends solely on the person himself, his innate characteristics, his desires, luck. However, it is difficult to agree with this. A person acquires his personality and individual characteristics in the process of active interaction with the world, with others. External circumstances of life are refracted through the inner person's world, influencing the content of the subject's psychological space. 
In Russian psychology, vitality is considered both as a general systemic mental property, and as an integral characteristic of a person, and as a special characteristic of a person, which reflects the effectiveness of the manifestations of functions responsible for effective adaptive behavior.

In foreign psychology, the concept of "resilience" is actively used. Resilience is interpreted as the ability to manage the resources of one's own health and use family, society, and culture for this at a socially acceptable level.

The concept of resilience came to psychology from engineering physics, where it characterizes the ability of solids to recover their shape after mechanical pressure.

With regard to the psychology of human life, resilience can be viewed as a person's response to a stimulus when the direction of movement is opposite to the direction of the applied force.

The phenomenon of resilience must be considered with the dynamic aspect: a person who has fallen into a difficult life circumstance and has received negative life experience in a traumatic situation is enhanced by this experience, since he copes with traumatization, becomes more resourceful.

Resilience of the personality is associated with the development of psychosocial competence, psychological culture, correlates with the experience of subjective well-being.

It is resilience that ensures effective adaptation to adverse life circumstances. At the same time, conditionally, the factors that contribute to successful adaptation at any level of risk can be divided into two groups:

1) compensatory factors;

2) protective factors.

It should be noted that resilience is a psychological phenomenon that is not a constant, unchanging quality of a person. One and the same person can in different life situations, at different moments of time, show and not show resilience.

In Russia, they began to conduct studies of resilience recently - only from the beginning of the 2000s. A.I. Laktionova notes that the beginning of the study of resilience in Russia was laid in 2002, when employees of the Institute of Psychology of the Russian Academy of Sciences began to conduct a psychological study on the viability of a person and a family, joining an international project to study the resilience of children and adolescents. The project leader was the American scientist M. Ungar, who proposed to consider resilience as the ability of a person to manage the resources of his own health and in a socially acceptable way to use his family, society, and culture for this.

In 2003 A.V. Makhnach proposed to actively use the term "vitality". A.V. Makhnach noted that the terms "resilience" and "vitality" can be used synonymously. According to him, vitality can be considered as a person's ability to overcome unfavorable life circumstances with an opportunity to recover, using for this all available resources, external and internal. According to A.V. Makhnach, vitality is the ability to live in all its manifestations, which is based on the will to live.

It should be noted that the very concept of "vitality" in Russian psychology was introduced a long time ago, back in the USSR, by B. G. Ananiev, who reflected on the potentials of personality development. The viability of B.G. Ananyev understood it as a person's ability to function effectively.

In Russian psychology, various authors have been involved in the study of viability. For example, Moscow researchers A.V. Makhnach and A.I. Laktionova described vitality as an individual person's ability to manage their own resources: health, emotional, motivationalvolitional, cognitive spheres in the context of social, cultural norms and environmental conditions. Dikaya L.G., Makhnach A.V., Laktionova A.I. presented the individual and socio-psychological factors of the viability of a professional [9]. Makhnach A.V., Laktionova 
A.I., PostylyakovaYu.V. turn to the comprehension and analysis of the viability and family resources of substituting parents [10].

Rylskaya E.A. and Vasilyeva S.N. considered the problem of constructing the definition of the concept of "professional viability" [11].

From the point of view of E.A. Rylskaya, the manifestation of vitality is expressed in satisfaction with one's own life, on the one hand, and helplessness, on the other. E. A.Rylskaya expanded the concept of vitality and identified its components (the ability for self-development, adaptation, self-regulation and meaningfulness).

The most prominent Russian researchers of viability are the following:

- A. A. Nesterova, author of her Ph.D. dissertation, dedicated to the description of the socio-psychological concept of the viability of young people in a situation of job loss. According to A.A. Nesterova, vitality is a systemic quality of an individual that characterizes the organic unity of individual and socio-psychological abilities of a person to realize resource potential, use constructive strategies of behavior in difficult life situations and in conditions of socio-economic deprivation, which ensures the return of the individual to the pre-crisis level of functioning and determines post-crisis personal growth;

- A. I. Laktionova, author of her Ph.D. thesis on the topic "The relationship of vitality and social adaptation of adolescents." A.I. Laktionova considers human vitality as a metasystem formation, the components of which are the individual's ability to reflect, acting as a metaprocessing regulator of human activity (activity, behavioral, communicative), which determines the way of individual integration of factors of the social environment;

- E. A. Rylskaya, author of a doctoral dissertation on the topic "Psychology of Human Vitality" E.A. Rylskaya adheres to the psychological concept of human vitality based on the communicative methodology.

Of particular interest is the integrative approach of A. V. Makhnach [12-15]. A.V. Makhnach develops a four-dimensional ecological model of M. Ungar, which includes the following aspects:

1) personality traits and individual characteristics;

2) relationships with loved ones;

3) the influence of society and the state;

4) inclusion in the cultural tradition.

Table 1. Representations of Russian researchers about viability as a psychological phenomenon.

\begin{tabular}{|l|l|}
\hline B. G. Ananiev & understood it as a person's ability to function effectively \\
\hline A. V. Makhnach & $\begin{array}{l}\text { a person's ability to overcome unfavorable life circumstances with } \\
\text { an opportunity to recover, using for this all available resources, } \\
\text { external and internal, vitality is the ability to live in all its } \\
\text { manifestations, which is based on the will to live }\end{array}$ \\
\hline A.I. Laktionova & $\begin{array}{l}\text { a metasystem formation, the components of which are the } \\
\text { individual's ability to reflect, acting as a metaprocessing regulator of } \\
\text { human activity (activity, behavioral, communicative), which } \\
\text { determines the way of individual integration of factors of the social } \\
\text { environment }\end{array}$ \\
\hline E. A. Rylskaya & $\begin{array}{l}\text { expanded the concept of vitality and identified its components (the } \\
\text { ability for self-development, adaptation, self-regulation and } \\
\text { meaningfulness) }\end{array}$ \\
\hline A. A. Nesterova & $\begin{array}{l}\text { a systemic quality of an individual that characterizes the organic } \\
\text { unity of individual and socio-psychological abilities of a person to } \\
\text { realize resource potential, use constructive strategies of behavior in } \\
\text { difficult life situations and in conditions of socio-economic } \\
\text { deprivation, which ensures the return of the individual to the pre- } \\
\text { crisis level of functioning and determines post-crisis personal } \\
\text { growth }\end{array}$ \\
\hline
\end{tabular}


In the studies of A.V. Makhnachsix interrelated components were identified (the most important properties and characteristics of a person that form his resilience (five internal and one external):

1) self-efficacy is a phenomenon that allows a subject, confident in his ability to mobilize cognitive resources to influence a particular life event, to make efforts, take actions, overcome obstacles in order to achieve a set goal;

2) perseverance as a manifestation of perseverance, self-discipline, the desire to continue the struggle to restore balance, being actively involved in the development of new goals, plans, if their initial options were not successful;

3) coping and adaptation - a set of cognitive and behavioral strategies that a person uses to manage needs in adverse conditions, and the process of adaptation to changing or unfavorable circumstances;

4) internal locus of control - the aspect of a person's perception of his ability to influence the environment and the course of life in the future, how much he believes that he himself is the initiator of everything and is responsible for everything that happened in his life;

5) family / social relationships - especially important relationships, as they are a source of emotional support and resilience;

6) spirituality / culture - the level of spiritual and moral development of a person, which generates and maintains a "sense of hope" in a person.

Barnard C.P. identified and described nine important phenomena that are positively correlated with vitality:

1) the child in childhood was accepted and surrounded by care and tenderness (especially in infancy);

2) no siblings before the child is 24 months old;

3) high level of intelligence;

4) skills to develop close and warm relationships;

5) a high level of motivation for achievement in school and outside;

6) the ability to construct productive meanings for the awareness of events occurring in life, which, in turn, leads to understanding and acceptance of these events;

7) the ability to selectively temporarily release from some obligations related to family and household, to realize their potential in other spheres of life (work, study, hobbies), and then, upon returning, constructively interact within the family system and create strong family ties;

8) internal locus of control;

9) the absence of serious injuries and illnesses during adolescence.

\section{Discussion}

Numerous empirical studies by various researchers confirm the existence of a reliable relationship between vitality and the following personality characteristics:

- adaptability;

- flexibility;

- extraversion;

- benevolence;

- openness;

- self-esteem;

- self-control;

- achievement motivation;

- goal setting;

- ego stability and ego control; 
- the ability to predict the threat, hazard situations;

- optimism;

- hope;

- creative potential;

- the ability to forgive.

According to research psychologists, the manifestation of vitality is influenced by some environmental factors:

- availability of social support,

- constructive parenting styles,

- presence of parents,

- emotional attachment and emotional support of parents,

- establishing and maintaining clear boundaries of what is permitted,

- encouraging a mindset for a reasonable division of responsibilities,

- ensuring access to resources that are necessary to meet current needs,

- expressing realistic expectations in terms of achieving success,

- recognition of achievements,

- support for the development of social values,

- providing leadership in decision making, etc.

According to the researchers, the internal (personal) factors that contribute to the development of the vitality of the personality, in fact, are the main characteristics of the psychological portrait of a resilient personality:

1) the use of certain life strategies: making good decisions, receptivity, control of impulsivity, focus on solving problems;

2) social activity, communication skills, the ability to have friends, build positive relationships;

3) a sense of humor;

4) self-control;

5) autonomy, independence, independence;

6) a positive image of your own future;

7) flexibility;

8) the ability to learn and apply what has been learned in practice;

9) the ability to self-motivate;

10) competence;

11) a sense of self-esteem and adequate self-esteem;

12) the ability to be part of a team;

13) initiative;

14) creativity;

15) moral stability, etc.

Due to the fact that vitality can be considered as a kind of survival strategy (personal, social, cultural), a strategy for overcoming unfavorable life circumstances, a significant role in providing the necessary assistance and the development of vitality is assigned to professional psychologists, in particular, counseling psychologists, and other specialists of the helping profile. In practical work focused on the development of the vitality of the client's personality, it is necessary:

- reinforce the focus on the discovery of client resources,

- consider the peculiarities of the organization of the client's living space, his environment,

- actively show empathy and reflexive abilities and skills,

- show interest in the client's life story, be a good listener,

- strive to establish trusting relationships and develop deep communication, dialogue in relations with the client, 
- focus on optimizing the client's self-esteem, developing his assertiveness, sense of humor, flexibility, creativity, etc.

\section{Conclusions}

Summarizing what was said above, it should be noted that, despite the fact that viability is a relatively new concept, there are a large number of different theoretical approaches, and an array of empirical data has been accumulated.

In Russian psychology, vitality is considered both as a general systemic mental property, and as an integral characteristic of a person, and as a special person's characteristic, which reflects the effectiveness of the manifestations of functions responsible for effective adaptive behavior.

Vitality is seen as the ability to cope with one's own life, the result of positive adaptation despite adverse conditions and / or dangerous circumstances. Vitality is characterized by a combination of social and intrapsychic processes that allow a person to be healthy in an unfavorable environment.

The manifestation of a person's ability to cope with difficult circumstances, unfavorable life situations is influenced by various factors, including the possibility / impossibility of productive self-expression, sufficient involvement / non-involvement in taking care of oneself and important life processes, searching and finding a solution to the problem of lack of motivation, openness / closeness, awareness / lack of awareness, etc.

An essential point in the development of a person's vitality is the provision of the necessary specially organized psychological assistance aimed at optimizing the client's selfesteem, developing his assertiveness, sense of humor, flexibility, creativity, motivationalsemantic sphere and reflective culture.

\section{References}

1. B. Daniel, S. Vincent, E. Farrall, F. Arney, How is the Concept of Resilience Operationalized in Practice with Vulnerable Children? International Journal of Child \& Family Welfare 1, 2-21 (2009)

2. A.J. Zautra, J.S. Hall, K.E. Murray, Resilience: A new definition of health for people and communities, Handbook of Adult Resilience / J.W. Reich, A.J. Zautra, J.S. Hall (Eds.) (New York, London: Guilford Press, 2010)

3. D. Fletcher, M. Sarkar, Psychological resilience: A review and critique of definitions, concepts and theory, European Psychologist 18, 12-23 (2013) DOI: 10.1027 / 10169040 / a000124

4. O. Hjemdal, O. Friborg, S. Braun, P. Fossion, The Resilience Scale for Adults: Construct Validity and Measurement in a Belgian Sample, International Journal of Testing 11, 5370 (2011) DOI: 10.1080 / 15305058.2010.508570

5. T.D. Letzring, J. Block., D.C. Funder, Ego-control and ego-resiliency: Generalization of self-report scales based on personality descriptions from acquaintances, clinicians, and the self, Journal of Research in Personality 39, 395-422 (2005) DOI: 10.1016 / j.jrp.2004.06.003

6. G. Windle, D.A. Markland, R.T. Woods, Examination of a theoretical model of psychological resilience in older age, Aging and Mental Health 12 (3), 285-292 (2008) DOI: 10.1080 / 13607860802120763

7. I. Strnadova, Stress and resilience in families of children with specific learning disabilities, RevistaComplutense de Educación 17 (2), 35-50 (2006) 
8. I. Salisu, N. Hashim, A Critical Review of Scales Used in Resilience Research, IOSR Journal of Business and Management (IOSR-JBM) 19, 4, III, 23-33 (2017) DOI: 10.9790 / 487X-1904032333

9. L.G. Dikaya, A.V. Makhnach, A.I. Laktionova, Individual and socio-psychological factors of a professional's viability, Social and Humanitarian Sciences in the Far East 15, 4, 137-146 (2018) DOI: 10.31079 / 1992-2868-2018-15-4-137-146

10. A.V. Makhnach, A.I. Laktionova, Yu.V. Postylyakova, Viability and family resources of foster parents, Social and Humanitarian Sciences in the Far East 15, 4, 45-54 (2018) DOI: 10.31079 / 1992-2868-2018-15-4-45-54

11. S.N. Vasilyeva, E.A. Rylskaya, Construction of the definition of the concept of "the viability of a professional", Yaroslavl Pedagogical Bulletin 2 (107), 106-113 (2019) DOI: 10.24411 / 1813-145X-2019-10358

12. A.V. Makhnach, Resilience in russian youth, International Journal Of Adolescence And Youth 21, 2, 195-214 (2016) DOI: 10.1080/02673843.2013.815116

13. A.V. Makhnach, Trends in the study of the family and characteristics of the composition associated with its viability, Bulletin of the Russian State University for the Humanities. Series: Psychology. Pedagogy. Education 2, 37-50 (2019) DOI: 10.28995 / 2073-63982019-2-37-50

14. A.V. Makhnach, Characteristics of the composition of the replacement family and its viability, Bulletin of the Kostroma State University. Series: pedagogy. Psychology. Sociokinetics 25, 2, 46-51 (2019) DOI: 10.34216 / 2073-1426-2019-25-2-46-51

15. A.V. Makhnach, Human vitality as a subject of study in psychological science, Psychological journal 38, 4, 5-16 (2017) DOI: 10.7868 / S0205959217040018 